\title{
RAZÕES PARA A REJEIÇÃO DO AUTONOMISMO RADICAL NO DEBATE ACERCA DA AVALIAÇÃO MORAL DE OBRAS DE ARTE ${ }^{1}$
}

\section{Luísa Caroline Da Silveira Pogozelski²}

\begin{abstract}
RESUMO
No caminho para a fundamentação da crítica moral de obras de arte há de se enfrentar alguns desafios ainda impostos na contemporaneidade. Este artigo valeu-se em maior parte da argumentação moralista moderada de Noël Carroll, bem como de sua compreensão acerca de como este debate deve ser levado a cabo. A posição a ser enfrentada é por ele intitulada autonomismo radical, a qual é essencialista sobre o valor da arte. Apontamos os problemas na argumentação autonomista, buscando responder ao argumento do denominador comum e ao argumento da trivialidade cognitiva. Também defendemos um pluralismo acerca do valor da arte, propondo uma visão mitigada de experiência estética, o que tem como resultado conceber o âmbito do valor artístico como englobando diversos campos de valor, sendo o estético apenas um entre os demais.
\end{abstract}

Palavras-chave: Crítica de Arte. Crítica Moral da Arte. Autonomismo Radical. Moralismo Moderado. Esteticismo.

\begin{abstract}
The way to grounding the moral assessment of artworks stumbles upon the challenges that are still imposed in contemporary times. This article took avail, for the most part, of Noël Carroll's moderated moralist argumentation, as well as his insight about how this debate should be performed. The position to be confronted is named by him radical autonomism, which is essentialist upon art's value. We pointed out the problems in the autonomist's argumentation, seeking replies to the argument of the commum-denominator and the argument of cognitive triviality. We also advocated a pluralism over art's value, proposing a mitigated view of aesthetic experience, which entails that the scope of the artistic value includes many fields of value, the aesthetic being just one of them.
\end{abstract}

Keywords: Art Criticism. Art's Moral Assessment. Radical Autonomism. Moderate Moralism. Aestheticism.

\footnotetext{
${ }^{1}$ O presente trabalho foi realizado com apoio da Coordenação de Aperfeiçoamento de Pessoal de Nível Superior - Brasil (CAPES) - Código de Financiamento 001.

2 Doutoranda em Filosofia pelo PPGFil/UFPel. E-mail: luisa csp@hotmail.com.
} 
Cotidianamente tecemos comentários sobre obras de arte de forma a envolver questões morais, e não é o caso somente de leigos, mas também de críticos de arte. Insistimos em fazer tais declarações de cunho moral, ainda que a filosofia tenha deixado de lado por algum tempo a fundamentação dessa possibilidade. Quando falamos sobre uma dimensão "moral" das obras de arte estamos nos referindo a algo de forma a fazer sentido? Qual a fundamentação filosófica dessas afirmações? Uma obra de arte pode educar ou deseducar moralmente?

Essa ideia foi significativamente deixada de lado no período em que se desenvolveram teorias a partir da Kritik der Urteilskraft de Kant ${ }^{3}$ (com exceção de alguns românticos como Schiller), as quais foram bastante infelizes nas leituras que fizeram do autor alemão, conforme veremos. Um dos precursores do reavivar dessa preocupação teórica foi Tolstói. Embora a crítica de arte nunca tenha deixado de operar dentro da possibilidade da crítica moral, o debate acadêmico teve de esperar até meados do século XX para se dar de forma ativa.

Pretendemos apresentar argumentos de Noël Carroll, o qual deseja justificar de que forma o criticismo moral das obras de arte ${ }^{4}$ não só é cabível, como é parte fundamental da mesma (ao menos com relação a alguns tipos de obras). Hume e Aristóteles podem ser facilmente identificados como suas maiores influências, bem como a perspectiva emotivista contemporânea da moral (importante mencionar o quanto o presente estudo está centrado nas contribuições mais recentes sobre esta discussão). O autonomismo radical, como caracterizado pelo autor ${ }^{5}$, é o maior empecilho que poderia ser colocado a esta tarefa.

\footnotetext{
${ }^{3}$ Dado o escopo deste trabalho, infelizmente não poderão ser desenvolvidas as contribuições de Kant para o campo da estética conforme interpretações hegemônicas. O autor é citado aqui apenas como "inspiração" bastante livre para as posições desenvolvidas pelos autores tidos como "autonomistas".

${ }^{4}$ A que este criticismo moral se refere? Ele poderia ir em três direções distintas: a) criticismo ético da maneira com que a obra foi feita; b) criticismo das consequências morais da obra (tan to no fenômeno micro quanto no macro, dizendo respeito, respectivamente às consequências no indivíduo e no meio social); ou c) crítica da perspectiva moral incorporada na obra (que a obra implicitamente defende). A discussão aqui presente refere-se somente às duas últimas possibilidades.

${ }^{5}$ Cabe aqui transcrever a taxonomia informada pelo autor acerca das posições de resposta ao problema. Seriam elas: 1) autonomismo radical: não permite comentários morais das obras de arte, pois associa elas somente ao reino do estético e afirma que a crítica moral incorre em um erro de categoria, produzindo apenas declarações sem sentido; 2) autonomismo moderado: afirma que é possível a crítica moral das obras de arte, porém essa não pode render avaliações acerca do valor geral das obras, pois o reino do estético se encontraria conceitualmente separado do moral, e por conseguinte, falhas/virtudes morais de uma obra não poderiam afetar seu valor estético; 3) moralismo radical: afirma que o criticismo ético é o único cabível, e sobrepõe os reinos moral e estético. Em todas suas versões não são possíveis avaliações variadas de obras de arte (assim, a arte seria totalmente boa ou má); 4) moralismo moderado: afirma que é possível que uma falha/
} 
O autonomismo seria uma escola relativamente recente na discussão, sobretudo quando consideramos o contexto histórico de seu surgimento. Ele é corolário da postura Esteticista, a qual, pode-se dizer, surge para tentar "salvar" a arte das garras do mau gosto burguês e da redução de tudo ao valor de mercado. O esteticismo (WHEWELL, 2009, p.128) é uma doutrina que diz que a arte deveria ser valorada por ela mesma, não por outros motivos como função, utilidade ou propósito.

A nobre tarefa da tese que daria impulso ao l'art pour l'art foi antes colocar-se do lado oposto ao moralismo radical do espectro, resguardando a arte de ser escrava de uma educação moral, ou alvo de críticas moralistas (em um sentido claramente pejorativo e "vitoriano"), garantindo-lhe um local "intocável" e exclusivamente seu. O movimento nasceu na França, no início do século XIX, e teve como principais nomes figuras como Charles Baudelaire, Gustav Flaubert, Oscar Wilde e Theóphile Gautier (DAVIES, 2009, p.128), os quais claramente zombam e criticam em seus escritos da tendência "moralizante" que a sociedade da época demonstrava no contato com suas obras.

Uma hipótese mais historicamente específica é a de que o Esteticismo foi uma resposta ao triunfo da cultura burguesa no século XIX, em cuja época a tendência dominante era reduzir todo valor a valores instrumentais e/ou comerciais. [...]O Esteticismo neste contexto, portanto, era um gesto de resistência cultural. Ele caracterizava a arte (ou o que algumas vezes chamamos de "arte elevada") como uma fonte de valor esotérico, separada dos valores cotidianos do comercialismo, da moralidade, e de qualquer outro tipo de propósito instrumental ou prático. O Esteticismo tentou vedar a arte hermeticamente das culturas burguesa e de massa ao declarar que a arte é autônoma. (CARROLL, 2010, p.237, tradução nossa)

O Esteticismo forneceu as diretrizes para resolver alguns problemas que assolavam a arte em seu momento. Um deles era a questão do estatuto da pintura após a invenção da fotografia, a qual tomou para si diversos dos papéis sociais que antes eram responsabilidade da pintura (como o de registrar acontecimentos de relevância histórica). Com o aparecimento das vanguardas artísticas e a progressiva força com que os artistas buscavam a

virtude moral venha acarretar uma falha/virtude artística, respectivamente. Porém, essa implicação, sobreposição ou correspondência nem sempre é defendida como necessária. Também são permitidos juízos variados, além de que esses podem referir-se somente a certos gêneros artísticos. 
independência de suas obras, fez-se necessária uma teoria que desse fundo a um novo olhar, preparado para deitar-se sobre as expressões que surgiam. Aos poucos a obra de arte se torna algo que pode ser pura criação e não precisa referir-se de qualquer modo ao mundo (como no caso de Kandinsky), podendo ser somente forma.

Por trás de máximas como a de Gautier "Nada é verdadeiramente belo a não ser aquilo que serve para nada; o que quer que seja útil é feio", encontramos a relação que o público deveria buscar ter com estas obras, pois era nesse tipo de pensamento que os artistas que se identificavam com o esteticismo buscavam se inspirar. Nesse contexto, teorias como a de Clive Bell surgem para dizer ao público que se encontra confuso: "procure por formas, por aquilo que se expressa de maneira puramente estética. Tudo que é verdadeiramente artístico não foi feito para ter qualquer utilidade".

Com esta tentativa de separação da arte de qualquer outro reino, a perspectiva que nasce com autores como Bell deseja inclusive resguardar a arte da esfera da moral. A denominação de sua posição na discussão do problema da arte e da moral (autonomismo, nos termos de Carroll) resume seu principal objetivo: tornar a arte independente de quaisquer fins a que possam submetê-la, torná-la autônoma. Esta disputa é visível no seguinte trecho de uma das cartas de Oscar Wilde redigida a um jornal que criticou seu romance, O Retrato de Dorian Gray:

A esfera da arte e da ética são absolutamente distintas e separadas. [...] O que tem importância é que um diretor de um jornal como o seu pareça sustentar a monstruosa teoria de que o Governo de um país deve exercer uma censura sobre a literatura imaginativa! (WILDE, 2003, p.1319).

Indignados com as reprimendas (acima de tudo hipócrita) da sociedade da época, que tentava impor sobre a literatura imaginativa sua pretensa moral pudica, os Estetas criticavam duramente sua moral. Poderíamos compreender estas disputas como demonstrando, por parte de Wilde, por exemplo, que atribuía à arte forte papel e impacto moral. No entanto, autores que Carroll identifica como autonomistas tomaram o Esteticismo em outro viés. Eles defendiam que a arte possui valor por si mesma, ou pelas experiências estéticas únicas que possibilitam, o que consideraria apenas uma base parti-

6 "Il n’y a de vraiment beau que ce qui ne peut servir à rien ; tout ce qui est utile est laid...". 
cular para sua avaliação. Contudo, viriam a contribuir para a consolidação da arte como se tratando de um campo com propósitos únicos e particulares.

\section{A teoria de Clive Bell e o formalismo}

Tendo a arte abstrata em evidência e também formas de expressão inéditas, aparecem problemas que, em verdade, há muito já existiam para as teorias que pretendiam explicar a arte como representação ou como expressão ${ }^{7}$. A nova tentativa essencialista ${ }^{8}$ de definição da arte, com foco nas inovações de seu tempo, é a teoria da arte como forma.

Na experiência estética "pura" (COOPER, 2009, p.111), a qual deve ser buscada na relação com toda arte, vemos um quadro como se ele não representasse coisa alguma. Isto sugere um caminho pelo qual podemos facilmente superar as dificuldades enfrentadas pela arte não representativa. $\mathrm{O}$ principal autor desta vertente é Clive Bell, autor de Art (1914). De acordo com a leitura de Carroll (2003, p.89), embora a princípio ele desenvolva sua teoria voltado para a pintura e a escultura, a mesma estende-se até uma teoria geral da arte. Com isso, devemos interpretar as informações anteriores de forma a compreender que Bell não deseja afirmar que obras representativas não são obras de arte. Ele deseja, em verdade, delegar seu estatuto de arte a outra coisa que não seu conteúdo representativo, qual seja, sua forma.

Em sua análise da característica prevalecente em toda arte, Bell cunha o conceito de forma significante. Trata-se do traço particular que notavelmente torna as obras de arte capazes de absorverem seu expectador por aquilo mesmo que são, por seu padrão ou configuração de atributos, atraindo nossa atenção através de sua forma, pura e simplesmente. "Quando uma pintura é uma obra de arte genuína, ela se dirige à imaginação como as figuras da psicologia gestalt, impelindo o expectador a apreendê-la enquanto uma configuração organizada de linhas, cores, formas espaços, vetores e similares." (CARROLL, 2003, p.88, tradução nossa). A forma significante é

\footnotetext{
${ }^{7}$ Os dois primeiros capítulos da obra Philosophy of Art (1999) de Carroll oferecem uma esquematização útil das formulações dos argumentos das teorias da arte como representação e da arte como expressão, bem como os argumentos que propõem-se a refutá-las.

${ }^{8}$ Carroll denomina "essencialista" toda teoria que visa definir a arte a partir de uma única característica que se pretende encontrar em todas obras. Em seguida também veremos o essencialismo a respeito do valor da arte, que diz respeito a outra discussão que não sobre a definição do que seja arte.
} 
“o néctar" do Esteta, tendo caráter de exclusividade à arte. É o que, estando presente no objeto, por si mesma é capaz de oferecer experiência estética ao observador, de maneira que:

Qualquer x é uma obra de arte se e somente se x possui forma significante. A posse de forma significante é uma condição necessária para o status de uma obra de arte; ou seja, algo é uma obra de arte somente se possui forma significante. E forma significante é uma condição suficiente para o status de obra de arte; se algo possui forma significante, então se trata de uma obra de arte'.

Para o autor defensor do moralismo moderado (corroborado por COOPER, 2009, p.111), o formalismo foi uma das implicações que muitos derivaram da noção de desinteresse apresentada por Kant na Kritik der Urteilskraft (1790), tanto artistas quanto teóricos e críticos. Segundo esta interpretação, nossa experiência das obras de arte se dá desinteressadamente: a partir do momento em que olhamos para o objeto em questão como um fim em si mesmo, e não um meio para algo (ou seja, olhamos sem interesses práticos). Deste modo podemos compreender porque o conteúdo representacional perde sua relevância para os formalistas.

Neste contexto argumentativo, a experiência estética é definida como centrípeta. Ocorre na experiência subjetiva de cada expectador que, se é capaz de colocar-se nesse estado, é capaz de compreender a experiência e o valor legítimo que ela carrega em si. A mesma característica capaz de roubar nossa atenção é também aquilo que define o domínio próprio à arte. Dentro desta lógica, segundo Carroll (2010), ela teria seus méritos medidos a partir de realizações formais atingidas pelos artistas, e a capacidade que as mesmas teriam de oferecer experiências a seus expectadores.

O ponto de partida de todos os sistemas estéticos deve ser a experiência pessoal de uma emoção particular. Chamamos obras de arte a objectos que provocam esta emoção. Todas as pessoas sensíveis concordam em afirmar que há uma emoção particular causada por obras de arte. Não quero com isto dizer, evidentemente, que todas as obras de arte provocam a mesma emoção. Pelo contrário, cada obra produz uma emoção diferente. Mas identificamos todas estas emoções como pertencentes ao mesmo tipo. Pelo menos até aqui, a melhor opinião está do meu lado. Penso que a existência de um tipo particular de emoção, provocada por obras de arte visuais, emoção causada por todos os géneros de arte visual (pinturas, esculturas, edifícios, vasos, gravuras, têxteis, etc.), não é contestada

9 Devemos esta formalização da teoria de Clive Bell a Noël Carroll. 
por ninguém que seja capaz de a sentir. Esta emoção chama-se emoção estética e, se formos capazes de descobrir alguma propriedade particular que seja comum a todos os objectos que a provocaram, então teremos solucionado aquele que considero ser o problema central da estética. Teremos descoberto qual a propriedade essencial de uma obra de arte, a propriedade que distingue as obras de arte de todas as outras classes de objectos. (BELL, 2009, p.2223)

A partir destas considerações, podemos inferir que o formalismo de Bell se estabelece a partir de três pontos: 1) a pressuposição de que, se existe uma condição necessária para algo ter o status de arte, deve se tratar de uma propriedade que todas obras possuam (o que, veremos mais adiante, é parte do argumento do denominador comum); 2) estabelece uma "função" básica, única e exclusiva para a arte, qual seja, a de exibir forma significante; 3 ) busca e atinge um poder explicativo alto, que consegue dar conta das mais variadas obras, pois ao ater-se a algo tão básico como a forma, consegue inclusive explicar nosso interesse em obras antigas, de caráter "obsoleto".

O formalismo mostra-se uma doutrina atrativa para aqueles que possuem inclinações "essencialistas", porque ele vai em busca de uma característica particular a todas as obras de arte, a qual justamente se trata da característica que distingue as mesmas de todas outras coisas no mundo. Com isso, compreendemos que ao estabelecer-se como teoria que deseja explicar a natureza de toda arte, o formalismo tem implicações importantes em nossa compreensão da apreciação artística, ou seja, naquilo que devemos buscar na arte, ou nos limites do que a arte pode nos oferecer (consequentemente, tem implicações sobre os limites daquilo que faz sentido criticarmos em uma obra).

\section{Má compreensão de Kant: refutando Bell}

Não é possível encontrar, nos textos de Bell, uma referência clara à noção de belo de Kant. Contudo, para Carroll (2001), fica claro que foi a partir desse conceito que o autor derivou a concepção de "emoção estética" a que se refere. Ele desenvolverá (predominantemente no capítulo "Beauty and the Genealogy of Art Theory", de Beyond Aesthetics) a tese de que a teoria estética da arte surgiu de uma "má leitura" de Kant, o qual teria escrito 
apenas uma teoria acerca do belo e temas da estética, sendo que parece não ter sido sua intenção proporcionar qualquer base para determinar o que é ou não arte (pergunta característica da área da filosofia da arte). Tal engodo teria levado certos autores a derivar uma definição de arte que se restringe a caracterizá-la esteticamente, predominantemente a partir de sua capacidade de oferecer experiências estéticas. "De fato, a teoria da arte é virtualmente reduzida à estética, enquanto a experiência estética é a "primeira entre iguais" das condições que a teoria propõe como sendo necessária para discriminar obras de arte de outras coisas" (CARROLL, 2001, p.20-21, tradução nossa).

Segundo o autor, essa redução é feita de forma intencional, a fim de nublar a distinção entre o artístico e o estético para tirar da mesa a intenção artística e as avaliações de obras de arte em outras áreas de valor (como moral e política). Carroll concorda com George Dickie em "limpar o terreno" da discussão e fazer distinções entre estética e filosofia da arte antes de tentar responder a quaisquer perguntas, pois teorias esteticistas como as de Hutcheson e de Kant que, curiosamente, encontravam seus melhores exemplos em belezas naturais, foram transpostas para a filosofia da arte. "Mais tendenciosamente, os últimos teóricos estão tratando a arte como se ela fosse uma subespécie da beleza". (CARROLL, 2001, p.23 tradução nossa).

Lembremos que o termo "Estética" foi introduzido por Baumgarten a fim de demarcar o reino da investigação acerca da percepção sensível em geral. Kant e Hutcheson, por sua vez, construíram teorias do Belo (no caso de Kant, também do Sublime), e não da Arte. Em busca da característica essencial a toda arte, Bell recorre a um estado sentimental ou experimental, que Carroll denomina de componente empírico. Este estado é referido explicitamente na afirmação de que "O ponto de partida de todos os sistemas estéticos deve ser a experiência pessoal de uma emoção particular”, o que, não nos custa muito para ver, carrega consigo problemas de objetividade para a derivação de qualquer conceito sobre o qual deseja-se erguer um sistema.

Em sua explicação, Bell apresenta conceitos interdependentes, resultando em uma argumentação circular. Pode-se identificar a arte a partir da experiência emocional da forma significante presente no objeto, mas como aprender a identificá-la? Quando solicitamos do autor que caracterize infor- 
mativamente seus conceitos, ele se apoia no movimento subjetivo do expectador. Ele pode acusar aquele que não identifica a forma significante de uma falta de sensibilidade, a qual, por sua vez, só pode ser conhecida a partir da experiência de verdadeiras obras, que a possuem. Ao que parece, aquele que é dotado da "verdadeira" sensibilidade artística é o que não discorda de Bell.

Atentas às acusações de circularidade e obscuridade sofridas por Bell, as teorias seguintes, que também pretendiam explicar a arte a partir de questões estéticas, ativeram-se à definição de experiência estética. A partir dela, esperaram ser capazes de identificar a arte, delimitar as possibilidades de criticismo, o valor da arte, etc., tais como as teorias de Monroe Beardsley, J.O. Ursom e John Dewey, que concebem nossa relação com as obras de arte como dependente de um estado em que o sujeito coloca a si mesmo (ou o estado resultante da exposição à obra de arte), que é diferente de qualquer outro, e se confina em apreciar somente características tidas como estéticas. Dentre os autores mencionados há diferenças em suas concepções de "estético". Variam de versões mais radicais, formais, até visões mais expandidas ${ }^{10}$.

\section{O Mito da Atitude Estética}

A partir desta outra estratégia de argumentação formalista, se definirmos experiência estética como uma experiência com valor em si, estaríamos excluindo a avaliação ética, uma vez que a ética levanta questões práticas em relação às artes ao invés de referir-se a um valor intrínseco da mesma. A crítica moral, que tanto nos interessa, é descabida deste ponto de vista.

A tese do autonomista na filosofia da arte serviu para alienar o questionamento filosófico na relação da arte com outras práticas sociais de forma a se igualar com o afastamento da arte moderna, sob a égide do autonomismo, da vida e da cultura em geral. Na filosofia da arte, isto resultou em uma perspectiva indevidamente restrita, até mesmo distorcida sobre a arte, a qual tem sido virtualmente cega diante de muitas dimensões que tornam a arte importante, tais como sua competência ética (CARROLL, 2010, p.161, tradução nossa).

\footnotetext{
${ }^{10}$ Como é o caso da teoria de Malcolm Budd, analisada por Robert Stecker em Aesthetics and the Philosophy of Art, mais precisamente no capítulo "Artistic Value".
} 
Esta visão foi debatida e se mostrou problemática, para Copper (2009, p.112), e principalmente para George Dickie, em seu artigo "The Myth of the Aesthetic Attitude".

Pretendemos demonstrar que não há razões suficientes para partirmos de uma visão essencialista da arte (que, de forma geral, identifica valor artístico com valor estético), a qual, para nossos interesses, é bastante limitadora uma vez que os chamados "Novos Críticos", escola com a qual Monroe Beardsley se identifica, tem como implicação de sua posição direcionarem-se para as falácias da 1) intencionalidade, 2) genética, e 3) afetiva (CARROLL, 2010c, p.6) (chamá-las de falácias já expressa o ponto de vista destes autores). Os novos críticos pretendem mostrar aquilo em que o público e a crítica devem prestar atenção na obra de arte, e nisto não estaria: 1) a intenção do artista; 2) as condições causais da apresentação da obra; 3 ) a resposta afetiva provocada pela obra. O foco dos Novos Críticos é isolar a arte no âmbito do estético, e isto, mais uma vez, impossibilita o criticismo ético como criticismo das obras de arte qua arte.

Para o teórico Monroe Beardsley, "Uma obra de arte é algo produzido com a intenção de oferecer a capacidade de satisfazer o interesse estético" (1983, p.98). A fim de evitar a circularidade, troca a noção de emoção estética de Bell pela experiência estética, e a caracteriza de outro modo que não focando-se na forma do objeto. Beardsley possui uma descrição da experiência estética que se orienta pelo afeto, e que analisa sua estrutura interna de sentimentos. Para ele, as cinco características relevantes da experiência estética são: a orientação pelo objeto, a liberdade sentida, o afeto destacado, a descoberta ativa e a totalidade (BEARDSLEY, 1982).

Interessante notar que, segundo Shelley (2015), o termo "desinteresse" em Kant era aplicado aos prazeres, estritamente. Nos teóricos esteticistas, ele parece ter migrado para as atitudes ${ }^{11}$. Portanto, é fácil compreender porque o teórico da atitude estética afirma que devemos manter certa atitude

\footnotetext{
11 Shelley elenca Schopenhauer como o primeiro grande teórico da atitude estética: enquanto para Kant o prazer desinteressado é o meio pelo qual descobrimos que as coisas contém valor estético, para Schopenhauer, a atenção "will-less" é ela mesma o locus do valor estético. A contemplação estética está livre das amarras em que cotidianamente nos colocamos e que moldam nossa atenção de acordo com a realização de nossos desejos (o que é doloroso). Desta forma, ela é epistêmica e hedonisticamente valorosa.
} 
não-prática frente ao objeto artístico: o juízo de gosto de Kant é contemplativo.

As ideias de George Dickie apresentadas em seu artigo "The Myth..." tiveram forte impacto sobre a pesquisa na área. Para Carroll, este trabalho pode ser lido como "uma demolição ${ }^{12}$ da noção de "estética" para o propósito último de minar as teorias da arte" (CARROLL, 2001, p.2, tradução nossa). O artigo evoca em seu título a polêmica que seria levantada, e que reflete uma visão menos ilusória do modo com que nos relacionamos com a arte. "Suspeito que há várias confusões envolvidas na suposição da incompatibilidade da atenção estética e os aspectos morais da arte, mas não tentarei tornar isto claro, uma vez que a raiz da suposição - a atenção desinteressada - é uma noção confusa.” (DICKIE, 1964, p.63, tradução nossa).

Segundo Cooper (2009), Dickie não apenas mostra em seu artigo que não há qualquer estado único da mente ao qual devemos nos induzir quando em frente a uma obra de arte (a chamada "distância psíquica"), como também não parece haver diferença entre atenção estética "desinteressada" e atenção tout court. Em um exame atencioso dos exemplos colocados pelos defensores da atitude estética, Dickie expõe de que forma aqueles expectadores que, para o teórico autonomista, não estão prestando atenção "da maneira correta" na verdade exemplificam casos de clara desatenção. A seguir, sua argumentação se dividirá em dois momentos: de que forma a atitude estética consiste em um mito; e de que maneira esta ideia desvirtua a teoria estética.

A teoria mais robusta acerca da atitude estética é a de Edward Bullough, cujo termo central é o termo "distanciar-se", um verbo para denotar uma ação a qual ou constitui ou é necessária para a atitude estética. Outra variação é a de Jerome Stolnitz e Eliseo Vivas, cujo termo central é identificado por Dickie como sendo "desinteressado", usado como advérbio ou como adjetivo (1964, p.56). Segundo Shelley, isso significa assistir a um objeto sem qualquer propósito por detrás de assisti-lo, “aceitá-lo em seus próprios termos", permitir que ele mesmo guie nossa experiência. A atitude estética isolaria o objeto e nos focaria sobre ele.

\footnotetext{
${ }^{12}$ A noção de experiência estética já vinha se mostrando precária com os trabalhos de Marshall Corhen e Joseph Margolis.
} 
A questão da distância em Bullough se trata de uma "distância psicológica", deliberada ou não, à qual se chega através de um processo psicológico de colocar o objeto em uma posição na qual não se engaje com ele de forma prática. "Há, portanto, uma espécie de ação - de consciência - estar distanciado" (DICKIE, 1964, p.57, tradução nossa). A apreciação estética seria um tipo de feito a ser realizado

... ao colocarmos o fenômeno, por assim dizer, fora do alcance de engajamento com nosso eu prático presente; ao permiti-lo estar fora do contexto de nossas necessidades e fins - em suma, ao olhá-lo 'objetivamente' [...] ao permitir somente tais reações por nossa parte enquanto enfatizando as características objetivas da experiência, e ao interpretar até mesmo nossa afecção 'subjetiva' não enquanto modos de nosso ser, mas antes, enquanto características do fenômeno. (BULLOUGH apud SHELLEY, 2015, tradução nossa).

Se tudo que se quer dizer com "estar distanciado" significa que nossa atenção encontra-se no objeto, criar um novo termo técnico (explica Dickie) é desnecessário, pois não parece haver evidências de quaisquer tipos de atos ou estados de consciência a serem referidos por ele que sejam de outra natureza.

Coloquemos em análise um exemplo oferecido por Bullough, o marido ciumento que, ao assistir uma encenação de Othello, não consegue desviar seus pensamentos de voltarem-se para suspeitas acerca das ações de sua esposa. Para Bullough, o marido ciumento não pode ter a experiência devida da obra, pois não se encontra no estado distanciado requerido. Contudo, devemos concordar que tudo que vemos neste caso é uma questão de desatenção por parte do expectador que se perde em seus próprios pensamentos e por isso acaba não seguindo o decorrer da peça.

O outro modo de se conceber a atitude estética, o da atitude desinteressada, é defendido por Jerome Stolnitz e Eliseo Vivas. Nas palavras de Stolnitz, a definição de atitude estética é a seguinte: “... atenção desinteressada e complacente e contemplação de qualquer que seja o objeto da percepção, por ele mesmo, apenas" (apud DICKIE, 1964, p.57, tradução nossa).

Para exemplificar esta definição, Dickie nos coloca o exemplo de duas pessoas que atendam à mesma obra de arte, uma porque quer apreciar a obra por ela mesma, e outra com motivos ulteriores. Imagine uma pessoa que olha para "O Fuzilamento de 3 de Maio de 1808" de Goya porque acre- 
dita que a pintura tenha um valor por si mesma - ou valoriza a experiência por ela oferecida - e um crítico que precise de conteúdo sobre o que escrever; ou ainda alguém que vá a exposição das obras de Goya para acompanhar um amigo apaixonado por arte, mas que não compartilha do mesmo entusiasmo.

Seria o caso de que somente o primeiro estaria tendo a experiência verdadeira da obra? Como coloca Matthew Kieran, de maneira geral,

[a] atitude estética é caracterizada em termos de uma motivação distinta para se atender a obras. Mas isso não parece distinguir um tipo caraterístico de atenção perceptiva. Nos aproximamos de obras com interesses distintos. Alguém pode ir ver Goya porque está interessado na história do período, porque está interessado no tipo de material utilizado ou porque quer apreciar olhar para as obras enquanto pinturas. Mas a diferença não é tanto uma questão de atitudes distintas, mas de motivações distintas. (KIERAN, 2004, p.67, tradução nossa).

Ao analisar tais exemplos, pode-se pensar que em verdade a motivação é que é fundamental para que a experiência se efetive da maneira correta. Assim, não é o caso de que a falha em ter uma experiência estética parte de um tipo distinto de atenção.

O que o defensor da atitude estética gostaria de encontrar nestes exemplos são fontes de distrações, que tirariam o foco da atenção do expectador da obra. Como Dickie e Kieran bem observam, tudo que encontramos são variações nas intenções do expectador. Há como se prestar mais ou menos atenção a algo, mas há apenas uma maneira de se estar atento a um objeto, maneira a qual se coloca como oposta à desatenção e que não tem uma espécie de calibre regulado por motivações. Portanto, "pode ter sentido se falar, por exemplo, de ouvir música desinteressadamente somente se faz sentido dizer que se escuta música interessadamente.” (DICKIE, 1964, p.58, tradução nossa). Aqui, desinteressadamente significaria ouvir sem propósitos ulteriores. Ao que podemos notar, não há real distinção perceptiva entre efetivamente ouvir música (com propósitos ulteriores) e efetivamente ouvir música (sem propósitos ulteriores).

Uma consequência da posição desenvolvida por Stolnitz seria a de que a relação do crítico com a arte é diferente da relação do público com a mesma, pois ele está focado em fazer avaliações, enquanto uma pessoa qual- 
quer se deixaria levar, sendo capaz de responder emocionalmente à obra “... a apreciação (perceber com a atitude estética) e o criticismo (buscar razões para embasar uma avaliação de uma obra) são (1) distintos e (2) psicologicamente opostos um ao outro" (DICKIE, 1963, p.61, tradução nossa). Aprender a aperceber-se de questões técnicas (tais como a atuação, os efeitos visuais de um filme, etc.) comuns à análise do crítico parece, na prática, ter o efeito reverso ao que Stolnitz considera: este aprendizado tende a afiar nossa percepção, nos colocando em um modo "não preguiçoso" de atenção.

Além do mais, podemos refletir e tirar conclusões muito similares às do crítico sem nem ao mesmo percebermos. Este é um ponto fulcral da argumentação de Dickie, pois é importante demonstrar de que forma certas atividades podem ser concomitantes à experiência da obra. O que parece ocorrer efetivamente é justamente o contrário. Encontrar uma razão (para elogiar a fotografia de um filme, por exemplo) é uma conquista, como ganhar uma corrida (1964, p.64): acontece enquanto corremos (dentro da analogia, acontece enquanto o assistimos), portanto não compete espaço com a atividade. Em um exemplo do autor, quanto tempo demora para notarmos que a ação presente da personagem, em uma narrativa literária, não condiz com a personalidade apresentada por ela no capítulo anterior? Ao responder esta pergunta, notamos que quanto mais estivermos concentrados na obra, mais seremos capazes de notar coisas características da observação de um crítico.

Ainda na esteira das atividades concorrentes à atitude estética, outra consequência da argumentação do teórico da atitude, e a qual aqui se faz de maior importância para nossos interesses, é observada por Langfeld na seguinte passagem: “Ou estamos preocupados com a beleza do objeto ou com algum outro valor do mesmo. Tão logo, por exemplo, considerações éticas ocorram em nossa mente, nossa atitude muda" (apud DICKIE, 1964, p.63, tradução nossa). Langfeld coloca o exemplo de quando somos levados a não lermos um livro por não concordarmos com "sua moral". Isto, para ele, rompe a atitude estética. Ademais, há a distinção por nós anteriormente citada, entre interesses práticos (moral) e atenção desinteressada (estética).

Apesar dos esforços de Langfeld para manter ambas esferas separadas, Dickie sugere que colocar a visão moral da obra como parte dela talvez não seja a melhor descrição. No entanto, é o suficiente para compreender- 
mos que a obra mudaria drasticamente se tentássemos retirar a sua parte "moral". Desta forma, entendemos de que maneira a visão moral da obra é parte fundamental da mesma.

Dado que criticamos a visão robusta de experiência estética das teorias esteticistas, devemos nos perguntar de que maneira verdadeiramente nos relacionamos com as obras de arte. Em resposta, Carroll nos apresenta uma versão "mitigada" da mesma. Ele argumentará que nossas respostas às obras de arte não se resumem às respostas estéticas, e que os problemas da arte não giram somente em torno da estética. Carroll inicia afirmando que, geralmente, o conceito de experiência estética é utilizado como um tipo de "conceito guarda-chuva", sob o qual, espera-se, estão todas respostas acerca das obras de arte. Na perspectiva de Carroll, há vários tipos de respostas apropriadas às obras de arte, e a experiência estética é uma dentre várias.

... algo é uma experiência estética se envolve a apreciação do design ou a detecção de propriedades estéticas ou expressivas ou a contemplação da emergência das propriedades formais, estéticas ou expressivas de suas propriedades básicas, ou a combinação de quaisquer ou todas estas propriedades. (CARROLL, 2001, p.3, tradução nossa).

Contudo, na explicação deflacionária da experiência estética, não há disjunção necessária entre participar de uma experiência estética e de outras atividades tais como a interpretação, busca de razões ou avaliação moral, pois nosso modo de interagir frente à arte compreende diversas formas que não parecem estéticas em sua natureza, muito menos são redutíveis à experiência estética.

Declaradamente naturalista, Carroll acredita ser mais vantajoso explicar a experiência estética como um tipo de capacidade que, sendo vivida por seres como nós, provavelmente possui alguma vantagem evolutiva dentro da seleção natural. Essa seria uma via mais confiável do que a valoração da experiência "por ela mesma". A experiência estética estaria relacionada com (ou derivaria de) nossa capacidade de detectar padrões, o que é fácil de imaginar de que forma se trataria de uma vantagem evolutiva.

Em última análise, foram nossos poderes aguçados de detectar padrões que nos tornaram capazes de controlar o ambiente. Humanos com poderes aguçados de detecção de padrões são beneficiários da 
seleção natural. Isso é provavelmente o que explica nossa posse desse aspecto em nossa capacidade de experiência estética. (CARROLL, 2000, p.198, tradução nossa).

Por seu viés, esta explicação ainda ajudaria a elucidar porque motivo buscamos repetir essa experiência: através da experiência estética podemos exercitar e talvez até mesmo expandir nossa capacidade de detecção de padrões (o que também torna a experiência estética instrumentalmente valiosa). Interessante notar que os padrões apresentados em obras de arte são padrões criados por outros humanos, o que também auxilia exercitarmos nossas habilidades naturais de reconhecer o que nossos pares querem comunicar, sua "intencionalidade" (CARROLL, 2000, p.198).

\section{Argumentos autonomistas em detalhe: Argumento do denominador comum}

Segundo o argumento do denominador comum, o principal argumento para a defesa da posição autonomista, a arte precisa ser definida a partir de uma característica que seja comum e única a todas as obras de arte, a chamada "característica essencial".

Carroll atenta para o fato de que a aparente preocupação do autonomista em querer preservar a arte de críticas morais se dá em reflexo ao exagero cometido pela teoria que tem seu surgimento em Platão, que defende que a crítica da arte é sempre crítica moral. A preocupação do autonomista é a de salvaguardar a arte de moralismos extremos, chamando atenção para o aspecto estético da mesma. Portanto, se nem toda arte toca em questões éticas, a avaliação moral, segundo o argumento do denominador comum, deve ser descartada como forma de avaliar obras de arte, pois não é amplamente aplicável dentre o universo artístico. Se pensarmos na variedade de obras que existem, rapidamente nos damos conta de que o raciocínio do autonomista se ancora no fato de que há obras sobre as quais parece um disparate tecer considerações morais, como algumas telas de Robert Delaunay, por exemplo.

O autonomista volta-se, então, para a questão da experiência estética tanto para identificar aqueles objetos que se tratam de obras de arte quanto para avaliá-los. Como, para ele, é característica única de obras de arte serem feitas para proporcionar experiências estéticas, a medida em que estas são 
capazes de proporcioná-las passa a ser também critério para a valoração das mesmas. Torna-se uma questão de objetivo último: proporcionar experiências é a função que cabe à arte. "O pensamento de que a arte é valorosa por si mesma, em contra partida, é visto [pelo teórico autonomista] como implicando que não é valorosa por outras razões, especialmente cognitivas, morais e políticas." (CARROLL, 2001, p.296, tradução nossa).

O esteta (concordando com o moralista moderado) diria que obras de arte acusadas de serem claramente imorais podem ser, ao mesmo tempo, estética e artisticamente excelentes. Ele também se negaria a elogiar uma obra de arte unicamente pelo fato de ser concebida como "moralmente pura". Essas, no entanto, não são as mesmas inclinações do crítico moral radical, podendo este condenar a obra que exibisse uma perspectiva imoral. O esteta teme que o crítico ético esteja inclinado a reduzir completamente o valor artístico a alguma outra coisa, qual seja, o valor ético. Do ponto de vista autonomista, uma vez reconhecida uma obra de arte, ela "ganha a maior importância ética e colocamo-la fora do alcance do moralista" (BELL, 2009, p.28).

Será verdadeira a opinião do autonomista de que a arte é independente de outras práticas, e que a estética é um reino independente e totalmente autônomo? Dada a descrição de um processo inteiramente formalista de avaliação e identificação das obras de arte, será que é verdadeiro que, para compreendê-las e ter a experiência proporcionada pelas mesmas, interagimos com elas através, unicamente, de uma atitude desinteressada e da análise das estruturas gerais das obras?

É difícil responder que sim quando pensamos em obras como Por Quem os Sinos Dobram ou Anna Karenina, para citar dois exemplos recorrentes de Carroll. Como poderíamos compreender uma narrativa sem empregar conhecimentos anteriores, como os de história, psicologia humana, biologia, se é próprio do caráter da narrativa ser incompleta, pois não é possível (nem característico ou do interesse do autor) descrever tudo? Se é descrito em uma obra literária realista que dado personagem, em 1785 foi visitar seu primo em outra cidade, obviamente não imaginamos que ele o fez de avião, ou de carro, mas sim em uma carruagem, ou a cavalo, dependendo de seu status social. Dessa forma, utilizamos de nosso conhecimento de his- 
tória para "preencher" aquilo que não foi informado na narrativa. Igualmente, quando é o caso de alguma personagem, em dado contexto narrativo, perder um ente querido, não é preciso que o autor explique porque ela se sente enlutada e profundamente triste, pois dado nosso conhecimento da psicologia humana, inclusive esperamos que seja isso que a personagem faça, e será estranho se não o fizer sem que haja uma explicação com sentido para isso.

Para fornecer um exemplo onde o que ocorre é o emprego de um "conhecimento" moral, ou o uso de um "truísmo moral13" o qual já nos era sabido, Carroll declara ser impossível compreender o ponto de Dostoiévski em Crime e Castigo se já não soubermos que matar é errado. Antes, é preciso que tenhamos domínio sobre alguns truísmos específicos para podermos compreender o que Raskólnikov sente e, desta forma, seguir a linha necessária para a compreensão geral da obra, o que comprova que circulamos em outras áreas que não apenas a estética ao termos contato com obras de arte. Afinal, como poderíamos compreender um romance somente admirando sua forma?

Segundo nosso raciocínio, podemos concluir que, ao menos no caso de determinadas obras de arte, a experiência estética não acontece da mesma maneira que Bell descreve em Art, onde ela é desinteressada e contemplativa, sendo desencadeada diretamente pelas características formais apreendidas através da percepção. Clive Bell partia de um contexto artístico de ênfase nas artes plásticas, e que clamava por uma teoria formalista para admitir as obras criadas naquele período como sendo objetos de arte, tendo se focado, portanto, em autores de forte abstracionismo. O erro de Bell pode muito bem ter sido quando tentou estender sua teoria de forma a abarcar todos gêneros.

Contudo, deve-se admitir, o autonomismo presenteia a discussão com um insight bastante útil: há determinadas obras de arte sobre as quais não faz sentido discursar no sentido moral, o que se deve ao seu conteúdo (ou ausência do mesmo), pois certas obras pedem unicamente que prestemos atenção em suas formas, cores, harmonia de elementos... Entretanto, "valo-

\footnotetext{
$\overline{13} \mathrm{O}$ autonomismo está certo em dizer que não há maneira de termos aprendido truísmos morais unicamente através de uma obra de arte narrativa (assim como o argumento do trivialismo cognitivo declara, ponto que veremos adiante). Porém, Carroll está aqui "concedendo" ao autonomista radical seu caso mais extremo para mostrar que ainda há outras formas pelas quais a arte pode estar atrelada à moral.
} 
rarmos a arte pela forma com que ela comanda integralmente nossa atenção não torna impossível que algumas obras de arte comandem nossa atenção desta forma somente porque são interessantes e engajantes cognitivamente e/ou, para nossos propósitos, moralmente." (CARROLL, 2001, p.278, tradução nossa).

Mesmo no caso de identificarmos um denominador comum, não resultaria disto que tal propriedade constituidora fosse necessariamente a única medida a ser considerada quando avaliássemos obras de $\operatorname{arte}^{14}$. "O pensamento de que a arte é valorosa por si mesma, em contrapartida é dita como implicando que não é valorosa por outras razões, especialmente cognitivas, morais e políticas. Contudo, esta conclusão é non sequitur". (CARROLL, 2001, p.278, tradução nossa).

Com isso, nos parece que a arte não participa somente da esfera estética. Devemos reconhecer que é o caso que algumas obras realmente não se relacionam diretamente com a moral. Mas não se segue disso que nenhuma obra seja objeto apropriado para o criticismo ético, tal como defende o argumento do denominador comum, pois esta conclusão não se segue das premissas do argumento. Ademais, a partir da argumentação aqui defendida, parece ser o caso de que algumas obras podem absorver nossa atenção justamente porque engajam (dentre outras coisas possíveis) a vida moral de seu público.

Carroll ainda cita outros motivos para deixar de lado a explicação autonomista: avaliar a arte a partir do princípio universal de sua capacidade de proporcionar experiências estéticas também parece ser um erro na medida em que identificamos haver obras de arte que desafiam a própria noção de forma, principalmente na contemporaneidade (como a obra 4:33 de John Cage). Além disso, alguns objetos que identificamos como sendo obras de arte não são feitos para contemplação. Algumas pretendem provocar pavor ${ }^{15}$, ou proteger e abençoar o local em que são colocadas. É o caso das esculturas Tiki do povo Maori, ou de afrescos e imagens esculpidas do cristianismo

\footnotetext{
${ }^{14}$ Neste momento fica claro como ocorre, na argumentação autonomista, a compreensão do termo "estético" como idêntico a "artístico", ou englobando apenas o que for de interessante permanecer sob o "guarda-chuva".

15 "Pavor" como aqui colocado significa que o sentimento que o objeto desperta em seu es pectador é capaz de afastá-lo, longe de se tornar um objeto passível de ser algo de contemplação. Não possui relação com os sentimentos trágicos mencionados por Aristóteles.
} 
primitivo. Lembremos também que o autonomista não admite que as obras usem de subterfúgios tais como a incitação de emoções como preparação do terreno para a experiência estética. Para o autonomista, ela é aquilo que sentimos a partir da apreensão direta das características formais do objeto e não se trata de qualquer emoção cotidiana (como compaixão, medo, suspense, temor, etc.).

Contudo, se os autonomistas não aderirem ao critério da arte ter sido feita para provocar experiências estéticas e requererem apenas que elas forneçam tal coisa, “...eles perdem o critério único à arte, uma vez que, putativamente, cachoeiras e pássaros contentes oferecem o tipo de experiência sobre o qual eles estão falando" (CARROLL, 2000b, p.359, tradução nossa).

Para o filósofo norte-americano, ainda mais problemático é notar que, ao longo de todo texto de Bell, não é possível compreender de que se trata exatamente a forma significante. O conceito central da obra, peça chave da argumentação, está permeado de obscuridades. Mesmo quando tentamos chegar até ele por outra via, a experiência estética, indicadora da presença de forma significante em um objeto, tais conceitos demonstram sua dependência e sua relação, dentro da argumentação do autor, em um círculo que não é nada informativo.

O defensor do moralismo moderado ainda apresenta três razões pelas quais não faz sentido temer, como o autonomista, que o crítico ético acabe por reduzir o valor artístico ao valor ético: a) diferentemente das teorias de base platônica, não é o caso que todo crítico ético se comprometa com a afirmação de que toda arte é passível de avaliação moral, pois não é necessário que o faça (e Noël Carroll não o faz); b) como nos exemplos desenvolvidos anteriormente, explicando de que forma estão envolvidas na apreciação das obras de arte muitas outras esferas além da estética, o moralista não se mostra tão estranho quando propõe falar de certas obras em termos da boa ou má percepção moral que estas apresentem. Se isso é feito levando em conta o tipo específico da obra em questão (se suas características são tais que propiciam e até clamam por comentários de cunho moral), não cabe objeção; c) também não é o caso que o crítico moral queira invalidar uma avaliação estética das obras, pois, igualmente, não há qualquer implicação que o leve a se comprometer com tal afirmação. "O criticismo ético 
é logicamente factível mas não devemos confundir o valor ético das obras de arte com seu valor estético" (CARROLL, 2010, p.244, tradução nossa).

É importante atentar ao fato de que mesmo obras que possuam uma dimensão ética ainda podem clamar por avaliação estética e ser, inclusive, contrabalanceadas por esta. Isso implica em duas possibilidades: o defeito moral pode ser tão pequeno ou a perfeição estética tão superior que a obra, ainda que imoral, no computo geral possua em sua dimensão estética seu ponto mais forte; ou uma obra que pareça moralmente elogiável pode acabar por ser julgada como má obra em outros níveis, e que estes se sobressaiam ou porque o ganho moral é pequeno ou porque seus defeitos estéticos são gritantes $^{16}$.

\section{Resposta ao argumento da trivialidade cognitiva}

$\mathrm{O}$ argumento da trivialidade cognitiva, desenvolvido pelos teóricos do autonomismo, direciona-se especificamente a combater algumas afirmações drásticas do moralismo radical. O moralista, em suas críticas morais às obras de arte, parece elogiar as obras (e seu autor) como se elogiasse as descobertas morais das mesmas, e a educação moral que elas seriam capazes de proporcionar. "Como frequentemente feito, o criticismo ético da arte procede pelo isolamento de uma tese moral associada com ou implicada por uma obra de arte, e então prossegue ao elogiar a obra sob a luz de seus comprometimentos morais." (CARROLL, 2010, p.238, tradução nossa). Por conta de alguns críticos éticos agirem como se obras de arte fossem contribuições para o conhecimento, faz-se a pergunta do cético que muito interessa o autonomista: será realmente possível que obras de arte ofereçam conhecimento?

O problema com a arte, para o cético, é o de que uma obra como $A$ Cabana do Pai Tomás, a qual segundo alguns críticos morais ensina que a escravidão é má, na verdade fala de algo que: já era sabido pelo público; é o tipo de conhecimento moral que poderia ser melhor colocado em um tratado, por exemplo; não prova o que disse porque todos seus exemplos foram inventados (trata-se de uma ficção), portanto não traz argumentos em favor

\footnotetext{
${ }^{16}$ Mais detalhes sobre a forma com que este autor qualifica a crítica podem ser encontrados em trabalhos de minha autoria a serem publicados em breve. Em outro estudo, continuo a discussão da fundamentação do juízo de gosto de Hume contribuindo com a perspectiva de Carroll.
} 
de sua posição. Para que haja educação ou conhecimento moral proporcionado pela arte é exigido do cético: conhecimento moral proposicional; que este conhecimento seja da ordem das descobertas (comparação com a ciência); o qual a obra apoia com evidências, argumentos e análises.

É importante ressaltar que o seguinte desenvolvimento não objetiva, por parte de Carroll, salvar o moralismo radical, influenciado pela teoria platônica, das críticas feitas pelo argumento da trivialidade. Ao final de seu raciocínio, Carroll concorda com o autonomista sobre a arte não oferecer conhecimento em um sentido forte. No entanto, é de seu interesse que algum espaço seja resguardado para o criticismo moral das obras de arte, mesmo que se ancore em maior parte em uma versão mitigada de educação moral. Vejamos suas respostas aos argumentos levantados pelo cético.

Carroll adiciona à crítica do cético a questão de que o conteúdo moral das obras de arte (como a subjacente "lição" em Crime e Castigo) parece em verdade ter de ser parte, anteriormente, do repertório do público, pois do contrário a obra não seria plenamente inteligível. Dadas estas objeções, podemos prosseguir ao defendermos uma definição mais branda de conhecimento que não a proposicional: são considerados por alguns críticos tipos de conhecimento como "saber que", "saber como", e "conhecimento de como seria se" (CARROLL, 2010, p.245-247).

Esse conhecimento de "imaginar-se em determinada situação" é defendido como um conhecimento que nos prepara para situações morais que ainda desconhecemos, exercitando nossa capacidade de deliberação. No entanto, o problema com esta abordagem é bastante evidente: bsituações ficcionais diferem gritantemente das situações morais enfrentadas na vida real uma vez que o autor ou narrador da obra pode desempenhar uma espécie de papel omnisciente que nos informa acerca das intenções, desejos e pensamentos de quantas personagens desejar, o que está longe de ocorrer em nossa vida cotidiana (CARROLL, 2010, p.248).

Como a defesa do conhecimento moral proporcionado pelas obras de arte através da noção de conhecimento por acquaintance não parece funcionar, a saída para os questionamentos do cético se mostra viável pela abordagem chamada por Carroll de "abordagem do cultivo"17", a qual redireciona o

17 Abordagem que, segundo ele, Martha Nussbaum também defende. 
foco da defesa do moralista moderado: “... os defensores da abordagem da familiaridade [acquaintance] argumentam que a concepção de conhecimento do cético é muito limitada, os defensores da abordagem do cultivo mantém que a concepção de educação do cético é muito limitada. (CARROLL, 2010, p.250, tradução e grifos meus).

Nesta concepção de educação, as obras de arte são capazes de afiar as habilidades e capacidades eticamente relevantes quais sejam: as emoções, o poder de melhor discriminação perceptiva, a imaginação, a habilidade geral de conduzir uma reflexão moral. Isto acarreta em uma expansão de nossa compreensão moral, pois como o próprio nome desta abordagem nos indica, ela atribui à arte a capacidade de cultivar os talentos morais que já possuímos, culminando em uma definição mais branda, de "educação moral" (CARROLL, 2010, p.250). Segundo Noël Carroll, o cético aceita como conhecimento moral somente a aquisição de proposições perspicazes acerca da vida moral, portanto está respondida a objeção levantada pelo argumento da trivialidade a partir da estratégia de buscar uma definição mitigada de educação (no sentido de melhoramento do conhecimento já adquirido), não de conhecimento.

Dado o raciocínio exposto anteriormente, as avaliações passam a ser feitas com base na qualidade da experiência moral que as obras nos oferecem, possibilitando, por exemplo, maneiras de empregarmos conceitos abstratos de forma inteligível e apropriada. Um exemplo usado por Carroll como análise de caso (2011, p.286) é a obra Orgulho e Preconceito de Jane Austen, a qual nos ajuda a identificar formas de orgulho que são boas e formas que não o são, estimulando uma complexa utilização de nossos conceitos morais, de forma a nos tornar mais competentes enquanto seres participantes da esfera moral.

No exercício proposto por certas obras, é possível que aprofundemos nosso conhecimento moral a partir de novas conexões que façamos ou que nos tornemos capazes de solucionar casos difíceis que antes não conseguiríamos a partir da sucessão de aplicações de um dado conceito, pois a moral é permeada por conceitos intrincados e bastante abstratos que por vezes apenas dominamos superficialmente, tais como os conceitos de virtude e de justiça. Se encararmos o aprendizado como a aquisição de novas e 
desconhecidas proposições ou emoções, então a arte, no sentido desta argumentação, não ensinaria exatamente, pois depende antes do próprio conhecimento de ao menos parte destas proposições e conceitos como condição de sua própria inteligibilidade. O tipo de "conhecimento" que a arte proporciona para Carroll, neste caso, é o seguinte: “em mobilizar o que nós já sabemos e o que já podemos sentir, a obra de arte narrativa pode se tornar uma ocasião para que nós aprofundemos nossa compreensão do que sabemos e do que sentimos" (CARROLL, 2001, p.283, tradução e grifo nossos).

\section{Uma crítica e uma contribuição à argumentação de Noël Carroll}

Como colocamos, implícita à posição do autonomista há uma defesa de um essencialismo a respeito do valor da arte de forma geral. É de nosso interesse esclarecer porque Carroll destitui esta perspectiva indiretamente, e se filia a um pluralismo ${ }^{18}$.

Segundo Robert Stecker, o essencialismo, em sua versão mais robusta, afirma que valor artístico é: (1) um tipo unitário de valor. É aquilo que valoramos quando valoramos algo "como arte". (2) É um valor único da arte. Nada mais fornece esse valor. (3) É compartilhado por todas obras consideradas valiosas enquanto arte, em todas formas artísticas. (4) É intrinsecamente valoroso e torna a arte intrinsecamente valiosa (STECKER, 2010, p.222).

Ainda, segundo Stecker, a afirmação mais difícil de ser derrubada é a de que todas obras de arte possuem valor estético. Contudo, como já vimos a partir das críticas de Dickie e de Carroll, o emprego do termo "estético" pelos autores essencialistas não possui definição consensual, e aparenta ser utilizado como um termo "guarda-chuva" para o que se quer incluir dentre as possíveis respostas que obras de arte provocam, ou tudo que deseja-se aceitar entre o rol de suas características únicas.

Já a resistência à interação do valor ético-artístico se dá em duas bases: 1) o valor artístico deve ser identificado com o valor estético; 2)

\footnotetext{
18 Stecker (2010) diz identificar Carroll como um pluralista sobre o valor da arte. Em verdade, pode-se dizer que, qualquer autor que proponha a crítica ética das obras sem reduzir o valor artístico ao valor ético, compromete-se com a visão de que a arte possui pelo menos dois tipos de valores. Como e se esses valores interagem é outra questão. Mas admitir uma visão nãoes sencialista é um grande passo na direção proposta por Carroll.
} 
o valor estético de uma obra é distinto do ético. Segundo o autor, acabamos aceitando a primeira premissa porque é fácil confundir valor artístico com valor estético (talvez porque seja uma distinção muito pouco evidenciada nas teorias artísticas até então e que ainda cause confusão). Contudo, nossa resposta ao argumento do denominador comum apontou que, mesmo sendo o caso que o valor estético estivesse presente em todas obras de arte, não se seguiria disso que somente a crítica estética seja cabível (ou seja, não se segue disso que haja somente valor estético nas obras).

O pluralismo defenderia que: algumas propriedades artisticamente valiosas são encontradas somente em certas formas de arte; nenhum dos valores encontrados seriam únicos à arte; a arte é sempre extrinsecamente ou instrumentalmente valiosa; não há um tipo de valor que todas obras possuam enquanto arte (STECKER, 2010, p.222).

Esta concepção não se dá a partir da análise conceitual do que seja a arte, mas sim de análises empíricas a posteriori. Stecker defende que somente saberemos os valores que fazem parte da arte ao observarmos no mundo aquilo que o público busca ao acessá-la (STECKER, 2010, p.222-223). Portanto, sobre o valor moral das obras, se é um fato percebido que o público procura a arte a fim de encontrar valor moral, e que aparentemente faz parte dos objetivos do artista fornecê-lo em sua obra, o valor ético facilmente passa a ser parte dos valores artísticos ${ }^{19}$. É importante lembrar que a avaliação ética (seja positiva ou negativa), como defendida pelo moralismo moderado de Carroll, se diferencia da censura ou de um "teste" de adequação da perspectiva retratada na obra. Há autores como Matthew Kieran (2003, 2006) que, além de defenderem a liberdade artística nas mesmas bases da liberdade de expressão, argumentam que mesmo obras imorais podem nos oferecer algo valioso.

Para Alessandro Giovannelli (2007) a maneira como as perspectivas aqui criticadas se relacionam é um tanto confusa. Carroll afirma implicitamente que, aquele que defende uma nãoinfluência entre os valores moral e artístico, necessariamente se compromete com uma visão essencialista do valor da arte. Declara ele acerca da caracterização do autonomismo radical

\footnotetext{
${ }^{19}$ A sugestão de que obras devam ser julgadas a partir do público para o qual são direcionadas também tem sido defendida por Jerrold Levinson.
} 
feita por Carroll: “... é problemática de diversas maneiras, incluindo o fato de que, extrema como é, ninguém parece sustentá-la, [...][P]ara afirmar a irrelevância, de alguma forma, do valor ético para o valor artístico, um autonomista não precisa afirmar que obras de arte não podem ser julgadas eticamente.” (GIOVANNELLI, 2007, p.118, tradução nossa).

Alguns comprometimentos que Carroll vê nos autores colocados como autonomistas podem parecer forçosos, pois como Giovannelli coloca, é difícil encontrar uma declaração clara de Wilde ou de Bell que os comprometa indubitavelmente com esta posição. Em uma leitura atenta de Oscar Wilde, até mesmo do próprio prefácio de O Retrato de Dorian Gray, encontramos o suficiente para notarmos que ele não se compromete com este tipo de posição, dando a entender até mesmo que a moral não só é assunto recorrente do autor literário, como também, em sua fase madura, parece delegar à arte um papel moral na vida humana.

(1) o que Carroll chama de "autonomismo radical" é uma perspectiva com a qual nem precisamos nos ocupar; (2) o que Carroll chama de "moralismo radical", ao menos sobre algumas das caracterizações que ele fornece, também deveria ser excluído da discussão; (3) o que Gaut chama de "imoralismo extremo" também não é de nosso interesse; e (4) cada uma das posições acerca do criticismo ético deve ser concebida como relativa a quaisquer que sejam as dimensões éticas que se afirma serem relevantes ou irrelevantes para o valor artístico. (GIOVANNELLI, 2007, p.121, tradução nossa).

Giovannelli vê a taxonomia adotada como problemática e não-informativa $(2004,2007)$, uma vez que esta maneira de classificar as posições de resposta ao problema acaba por embaralhar questões que não necessariamente devem ser respondidas conjuntamente. Em seguida, o autor da crítica oferece uma nova taxonomia que pretende se referir somente às respostas dadas ao problema da interação entre o valor moral e o artístico, em um debate que seria levado a cabo somente por aqueles que já admitem essa possibilidade. Sendo assim, o autonomismo radical, como caracterizado por Carroll, não entraria na discussão uma vez que se trata de uma posição que não admite essa possibilidade. Seria o mesmo caso do moralismo radical (que afirmaria que todas obras são passíveis de crítica moral, e que a crítica 
moral escantearia qualquer outro tipo de crítica), argumenta o autor, pois ele se apresenta como um reducionismo.

A nova taxonomia sugerida seria a seguinte:

a) autonomismo radical: não nega que as obras de arte podem ser sujeitas à crítica ética, porém com a ressalva de que essa avaliação nunca pesa sobre a avaliação da obra enquanto obra de arte;

b) autonomismo moderado: o valor ético pode, por vezes, pesar sobre o artístico. No entanto, essa relação é sempre assistemática, seja em qualquer gênero artístico. Esta posição também daria vazão a posições "Imoralistas", pois como a relação é assistemática, também seria possível que a imoralidade de uma obra pesasse a favor de seu valor artístico, ou fosse mesmo irrelevante.

c) moralismo radical: afirma que o valor ético sistematicamente pesa sobre o valor artístico das obras, em toda e qualquer obra que possua uma dimensão moral, independentemente de seu tipo ou gênero (no sentido virtude moral $\rightarrow$ virtude artística; falha moral $\rightarrow$ falha artística);

d) moralismo moderado: o valor ético implica sistematicamente no valor artístico (no sentido virtude moral $\rightarrow$ virtude artística; falha moral $\rightarrow$ falha artística), porém a relação não se dá sobre qualquer obra de arte, variando entre tipos de obras (ficção realista, ou propaganda política, por exemplo);

No imoralismo, o valor ético pesaria sistematicamente no valor artístico, entretanto em uma relação inversa ao moralismo (no sentido virtude moral $\rightarrow$ falha artística; falha moral $\rightarrow$ virtude artística). Giovannelli atenta para o fato de que, uma perspectiva como esta, só faria sentido se fosse colocada como moderada, não defendendo uma relação sistemática de valores e em todos os gêneros ${ }^{20}$. O imoralismo também traz a possibilidade de pensarmos gêneros como a sátira (GIOVANNELLI, 2007, p.122-123).

Claramente, esta nova taxonomia se refere somente à discussão acerca da interação entre os valores moral e artístico, no sentido de que podem fazer parte da discussão somente aqueles que já admitem esta possibilidade. A de Carroll está interessada em mostrar uma visão mais abrangente. Talvez não isole tão bem as posições referentes à discussão específica do problema

${ }^{20}$ Como parece ser o caso de Matthew Kieran. 
da interação. No entanto, auxilia a compreendermos as teorias da arte (definição de arte, de propriedades estéticas, compreensão sobre nossa interação com as obras, etc.) que se encontram por detrás dessas posições acerca da crítica moral das obras.

Uma das discussões que acabaria sendo usada como critério para a divisão taxonômica de Carroll seria a do valor das obras de arte, mais especificamente a discussão acerca do pluralismo vs. Essencialismo. Como vimos, uma concepção essencialista está por trás das posições autonomistas. A taxonomia de Carroll se referiria, portanto, a pelo menos duas discussões: misturaria as posições acerca do valor da arte com as posições acerca da discussão da interação do valor moral das obras com seu valor artístico. Por definição, uma teoria essencialista do valor da arte que teria o valor estético como o valor essencial e único de toda arte não poderia participar da discussão acerca do problema da interação, pois ela simplesmente afirmaria que não há tal coisa.

A partir da perspectiva que deseja isolar o problema da interação, a taxonomia de Carroll não seria a mais desejada, uma vez que traz para a discussão distinções desnecessárias acerca de outras posições defendidas pelos autores em outros assuntos. Já a perspectiva de Giovannelli, ao focar somente no problema da interação, oferece uma maneira menos "engessada" e arbitrária de classificação, permitindo comprometimentos mais específicos e respostas mais detalhadas para cada posição defendida.

\section{Considerações finais}

Preocupamo-nos em responder à pergunta acerca de como e se é possível um fundamento para nossas avaliações morais de obras de arte, de maneira que essas afetem seu valor geral (artístico), utilizando a argumentação, em maior parte, de Noël Carroll em sua oposição ao autonomismo radical (como caracterizado por ele).

Ao responder o autonomista, o autor pressupõe uma revisão de algumas teorias esteticistas, pois afirma que as mesmas se ancoram em uma má compreensão da teoria kantiana. Dada a importância dessas teorias, e também a contundência dos argumentos de Carroll, bem como os de George 
Dickie, a crítica que expomos atenta para uma correção que deve ser feita de inúmeros conceitos e concepções das quais os autores se utilizam quando pensam sobre a arte.

O autor carece de uma solução definitiva para o problema do emprego do termo "estético". Todavia, o diagnóstico de seu uso em algumas teorias é algo para o qual sempre devemos atentar, pois inúmeros são os autores que não têm o cuidado em seu uso, não esclarecem sua opção ou não a justificam, causando assim confusões que poderiam ser evitadas.

O autonomismo radical, que se ancora mais fortemente no argumento do denominador comum, parece abalado pelas colocações de Carroll não só enquanto resposta ao problema da avaliação moral de obras de arte, mas também como teoria que postula uma visão essencialista de arte. Também buscamos oferecer razões para o comprometimento de Carroll com a perspectiva pluralista do valor da arte, a qual vem somar na defesa da avaliação moral das obras de arte, bem como a influência em seu valor geral.

As concepções do autonomista de forma significante e experiência estética se mostram ambas problemáticas. Também o belo e o sublime podem ser objetivos da arte se esta for a escolha do autor da obra, pois atrás destes ele pode buscar nos provocar ou representar o que deseja. Neste sentido, a estética buscaria compreender porque e como estas exercem atração sobre nós, o que de forma alguma implica em reduzir a arte a este objetivo, ou a reduzir o abrangente domínio da estética a ser confundido com a filosofia da arte (a qual, neste contexto, vem a ser aquela que estudaria todos efeitos das obras, não somente os do domínio estético). Estando no fundamento da posição, o abalo destes conceitos rende espaço para que uma nova noção de experiência estética seja apresentada, bem como uma reflexão acerca da real natureza de nossa interação com a arte.

\section{Referências}

ARGAN, Giulio C. Arte Moderna. São Paulo: Companhia das Letras, 1998.

BEARDSLEY, Monroe. "An Aesthetic Definition of Art". Em CURTER, Hugh (ed.). What is Art?. New York: Haven, 1983. 
$\overline{\text { University Press, } 1982 .}$

The Aesthetic Point of View. London: Cornell

BELL, Clive. Arte. Lisboa: Texto \& Grafia, 2009.

CARROLL, Noël. Art In Three Dimensions. Oxford: Oxford University Press, 2010.

. "Art and the Domain of the Aesthetic". British Journal of Aesthetics 40(2), 191-208, 2000.

. Beyond Aesthetics: Philosophical Essays. Cambridge, UK: Cambridge University Press, 2001.

. "Enjoyment, Indifference, and Aesthetic Experience". British Journal of Aesthetics 41 (1), 81-3, $2001 \mathrm{~b}$.

. Filosofia da arte. Lisboa: Texto \& Grafia, 2010b.

. "Formalism". Em GAUT, Berys \& LOPES, D.M. The Routledge Companion to Aesthetics. London, UK: Routledge, 2003.

. On Criticism. New York: Routledge, 2008.

. "On the Historical and Structure of Monroe Beardsley's Aesthetics: An Appreciation". The Journal of Aesthetic Education, Vol. 44, No. 1, pp. 2-10, 2010c.

. "Recent Approaches to Aesthetic Experience". The Journal of Aesthetics and Art Criticism Volume 70, issue 2, 2012.

Wisconsin Press, $2000 \mathrm{~b}$.

(ed.). Theories of Art Today. Madison: University of

COOPER, David E. “Aesthetic Attitude". Em DAVIES, S.; HIGGINS, K.M.; HOPKINS, R.; STECKER, R.; COOPER, D.E. A Companion to Aesthetics (2 $2^{\text {nd }}$ ed). Oxford: Blackwell Publishing, 2009.

DAVIES, S.; HIGGINS, K.M.; HOPKINS, R.; STECKER, R.; COOPER, D.E. A Companion to Aesthetics (2nd ed). Oxford: Blackwell Publishing, 2009.

DICKIE, George. "Beardsley's Phantom Aesthetic Experience". The Journal of Philosophy, Vol. 62, No. 5 (Mar. 4, 1965), pp. 129-136.

Philosophical Quaterly 1, p. 56-65, 1964.

"The Myth of the Aesthetic Attitude". American

GIOVANNELLI, A. Artistic and Ethical Values in the Experience of Narratives (Dissertação de pós-doutorado em filosofia), University of 
Maryland, College Park, USA. 2004, 403 f. Disponível em: http://drum.lib.umd.edu/bitstream/handle/1903/1474/umiumd1595.pdf;jsessionid=F2C922546C5EF48DE97129C898945FCB? sequence $=1$

"The Ethical Cristicism of Art: A New Mapping of the Territory". Philosophia 35:117-127, 2007.

KIERAN, Matthew. "Art, Imagination and the Cultivation of Morals". Em BERMUDÉZ, J \& GARDNER, S. (ed.). Art and Morality, London: Routledge, 2003.

. "Art, Morality and Ethics: On the (Im)Moral Character of Art Works and Inter-Relations to Artistic Value". Philosophy Compass $1 / 2$ (2006) 129-143.

. Revealing Art. London: Routledge, 2004.

LEVINSON, Jerrold. Aesthetics and Ethics: Essays at the Intersection. Cambridge, UK: Cambridge University Press, 1998.

MCLAUGHLIN, Thomas M. "Clive Bell's Aesthetic: Tradition and Significant Form". The Journal of Aesthetics and Art Criticism Vol. 35 No.4, p.433-443, 1977.

SHELLEY, James. "The Concept of the Aesthetic", The Stanford Encyclopedia of Philosophy (Winter 2015 Edition), Edward N. Zalta (ed.), Disponível em: http://plato.stanford.edu/archives/win2015/entries/aestheticconcept/, acesso em abril de 2016).

STECKER, Robert. Aesthetics and the Philosophy of Art: An Introduction ( $2^{\text {nd }}$ ed). Plymouth, UK: Rowman \& Littlefield, 2010.

WHEWELL, David. Aestheticism. DAVIES, S.; HIGGINS, K.M.; HOPKINS, R.; STECKER, R.; COOPER, D.E. A Companion to Aesthetics ( $2^{\text {nd }}$ ed). Oxford: Blackwell Publishing, 2009.

WILDE, Oscar. Obras Completas. Rio de Janeiro: Nova Aguilar, 2003. 